\title{
The Lung in AIDS
}

M. Mujahid Salim, M.D., Amatal B. Mir, M.B.

Stony Brook, New York

\begin{abstract}
AIDS has assumed epidemic proportions. The lungs are commonly involved and recurrent infections with opporlunistic organisms occur. These are relatively refractory to eradication. Newer agents have had some limited success against these organisms. A vaccine is currently under trial.
\end{abstract}

Key words: Acquired Immune Deficiency Syndrome, Human Immune Deficiency virus, pulmonary infections, new therapeutic agents.

\section{Introduction}

The discovery of Acquired Immune Deficiency Syndrome (AIDS) in 1981 has attracted more publicity and generated more fear than any infectious disease in recent times. Over 30,000 cases have so far been reported to the Center for Disease Control (CDC); $56 \%$ of these have died. The total number of AIDS cases has increased each year, about 7,000 cases being reported in 1986 alone. The estimated cost for the first 9,000 cases was more than $\$ 2.5$ billion.

\section{Epidemiology}

The major risk groups include homosexual males $(75 \%)$, intravenous drug abusers $(20 \%)$, blood product recipients ( $2 \%$, primarily hemophiliacs), infants and young children whose parents have AIDS and Haitian immigrants $(3.6 \%)$. The retrovirus causing AIDS is not transmitted by casual association, but through intimate sexual contact, sharing contaminated needles, transfusion of whole blood, blood cellular components, plasma, or clotting factor concentrates, and from infected mother to child perinatally.'

\section{Etiology}

In 1984 a retrovirus was identified as causing AIDS. ${ }^{2}$ This contains a single stranded RNA genome

From the Division of Pulmonary Medicine, Department of Medicine, Queens Hospital Center Affiliation of the Long Island Jewish Medical Center State University of New York at Stony Brook, New York.

Reprint requests: $M$. Mujahid Salim, M.D.

2726 Matlock Road, Suite C

Arlington, Texas 76014 and a DNA synthesizing enzyme reverse transcriptase. It was named Human $T$ cell leukemia virus, Type III (HTLV-III). Recently, this name was changed to Human Immunodeficiency Virus, HIV. This virus has been recovered from blood, saliva and semen of patients with AIDS. It infects and kills T-4 helper cells; lymphopenia, anergy and polyclonal elevation of serum immunoglobulins also occurs. HIV is also neurotropic, causing acute and chronic neurological diseases. Thus encephalopathy and dementia are often seen in AIDS patients. ${ }^{3}$

\section{Serologic testing}

An enzyme-linked immunosorbent assay, ELISA, to detect antibodies to HIV has been developed. It is $98.6 \%$ specific and $97.3 \%$ sensitive. The Western Blot method is more sensitive $(100 \%)$, but less economical. ${ }^{+}$Recently, monoclonal antibodies have been used to detect HIV antigens much earlier in the course of HIV infection.

\section{Diagnosis}

To make the diagnosis of AIDS, the $\mathrm{CDC}$ requires the presence of an unexplained opportunistic infection and/or unusual neoplasm in an individual with no recognized cause for such a susceptibility. Another diagnostic entity; AIDS Related Complex (ARC), occurs weeks to months prior to documented AIDS, and consists of nonspecific systemic symptoms (such as fever, fatigue, weight loss, wasting and diarrhea), generalized lymphadenopathy, localized opportunistic infections including oral candidiasis, and herpes zoster. Seropositivity for HIV antibody is found in $84 \%-100 \%$ of these patients.

\section{Clinical Manifestations of AIDS}

Pneumocystis pneumonia remains the most common infection found in $47 \%$ of newly diagnosed 
cases and $63 \%$ of all cases of AIDS. Kaposi's sarcoma is found in $24 \%$, Candidal esophagitis in $14 \%$, cytomegalovirus in $75 \%$, and all other infections have an occurence of less than $5 \%$ of patients with AIDS. Multiple infections are usually present and are difficult to eradicate. Inflammatory responses, e.g., granuloma formation are often absent. Radiographic patterns are nonspecific and do not help to distinguish between the different pathogens.

\section{Protozoan infections}

Pneumocystis carinii pneumonia (PCP): Compared with PCP in other immunosuppressed patients, e.g. those with neoplastic disease, or on steroid therapy, the onset of PCP in AIDS patient is insidious and prolonged (weeks to months). ${ }^{3}$ Fever, dyspnea, and non-productive cough may occur, sometimes progressing to respiratory failure. Pathologically, the lungs reveal massive consolidation on gross examination. Histologically, the alveoli are filled with a proteinaceous foamy, eosinophilic material containing pneumocystis cysts and trophozoites. These cause an inflammatory response in the interstitium, though not invading the epithelium. P. carinii does not grow in culture media, but does take up methenamine-silver, toluidine blue$O$, Gram and Giemsa stains and is also recognized by immunofluorescene. A chest roentgenogram often shows interstitial infiltrates and/or alveolar densities. It may, however, be clear initially. Arterial blood gases measurement show hypoxemia at rest or with exercise. A gallium scan shows a diffuse uptake while the diffusion capacity is decreased. Early bronchoscopy is preferred, and bronchoalveolar lavage has a high yield. ${ }^{6}$ The need for transbronchial specimens and open lung biopsy is thus reduced. PCP usually responds to treatment with trimethoprim/sulfamethoxazole (Bactrim, Septra) or pentamidine (Pentam 300) given for a minimum of two to three weeks.' Hypersensitivity reactions to these agents are much more frequent in AIDS than in other patients. Skin rash or leukopenia may occur with trimethoprim/sulfamethoxazole; ${ }^{8}$ while hypotension, local pain, hypoglycemia, hyperglycemia, hypercalcemia, peripheral neuropathy, hepatic, renal and hematologic dysfunction may be seen with pentamidine. Alphadifluoromethyl ornithine, DFMO, is an experimental agent showing promising results; reversible thrombocytopenia is one of its toxic effects. The combination of pyrmethamine and sulfadoxine (Fansidar) has been tried with initial success as a prophylactic drug. ${ }^{16}$ Stevens-Johnson syndrome may occur with this, especially in patients with skin hypersensitivity to Bactrim. Dapsone also has shown some effect on PCP. ${ }^{17}$

Finally, AZT (3'-azido-3'-deoxythymidine) appears promising in PCP treatment. ${ }^{9}$ It suppresses replication of the retrovirus, though reports of bone marrow suppression due to AZT therapy have recently been reported. Other protozoan infections like cryptosporidiosis and toxoplasmosis may abound in AIDS victims, involving the gastrointestinal tract and central nervous system, respectively.

\section{Bacterial infections}

A. Mycobacterium Tuberculosis is not often seen as an opportunistic infection in AIDS patients from the U.S.A. but may present earlier in the pre-AIDS or ARC stages. Severe tuberculosis is, however, seen in the Haitian AIDS patients, often presenting as extrapulmonary and/or disseminated disease. Mediastinal lypmphadenopathy, lower lobe and diffuse bilateral disease with absence of cavitation may occur. ${ }^{10,11}$ INH prophylaxis is suggested by some authors for Haitians with AIDS.

B. Mycobacterium avium intracellulare (MAI) causes a disseminated disease in patients with AIDS who present with fever, weight loss, abnormal liver function tests, and pancytopenia. In a study from Queens Hospital 3 out of 15 AIDS patients had MAI infection. Diagnosis is made on positive cultures from blood, lymph nodes, liver, spleen, or bone marrow specimens. MAI is the commonest bacteremia in AIDS. Positive sputum and bronchoscopic washings are considered by some to be adequate evidence of dissemination. Poor results have been obtained from treatment by conventional antituberculosis drugs and a combination of Ansamysin, Clofazimine and Ethionamide has been suggested. ${ }^{12}$

C. Other bacterial infections: AIDS is associated with an increased incidence of bacterial pneumonias, especially hemophilus influenzae and streptococus pneumoniae.

\section{Fungal infection}

A. Candidiasis: Candidal infection of the oropharynx, esophagus, and rectum is the commonest infection in AIDS. Dissemination rarely occurs and may be associated with pulmonary involvement. Oral Nystatin, Ketoconazole or Amphotericin $B$ may be used depending on the severity of the infection.

B. Cryptococcosis: The pulmonary infection this may induce is usually mild though the lung is usually the site of localization. The central nervous system is most frequently involved. Headaches, fever, nausea, vomiting, retinitis, lymphadenopathy and peritonitis may be present. ${ }^{12}$ The presence of $\mathrm{C}$. neoformans, antigens, and budding yeast in the cerebrospinal fluid clinches the diagnosis. Treatment with Amphotericin B plus 5-Fluorocytosine or high doses of Amphotericin B alone brings about a good initial 
Table 1. Pulmonary Involvement in AIDS

\begin{tabular}{|c|c|}
\hline Organism & Clinical Manifestations \\
\hline $\begin{array}{l}\text { A. Protozoa } \\
\text { i.Pneumocytis carinii } \\
\text { ii.Toxoplasma gondii }\end{array}$ & $\begin{array}{l}\text { Pneumonia } \\
\text { Encephalitis, } \\
\text { dissemination }\end{array}$ \\
\hline $\begin{array}{l}\text { B. Fungi } \\
\text { i.Cryptococcus neoformans } \\
\text { ii. Histoplasma capsulatum } \\
\text { iii.Aspergillus fumigatus } \\
\text { iv.Candida sp. dissemination } \\
\text { v.Mucor } \\
\text { vi.Coccidioi des Immitis } \\
\text { vii.Petriellidium Boydii }\end{array}$ & $\begin{array}{l}\text { Dissemination } \\
\text { Dissemination } \\
\text { Dissemination } \\
\text { Stomatitis, esophagitis, } \\
\text { Dissemination } \\
\text { Dissemination } \\
\text { Pneumonia }\end{array}$ \\
\hline $\begin{array}{l}\text { C. Viruses } \\
\text { i.Cytomegalovirus } \\
\text { ii. Herpes simples } \\
\text { iii.Herpes zoster-varicella }\end{array}$ & $\begin{array}{l}\text { Retinochoroiditis, } \\
\text { pneumonia dissemination } \\
\text { Dissemination } \\
\text { Dissemination }\end{array}$ \\
\hline $\begin{array}{l}\text { D. Bacteria } \\
\text { i.Mycobacterium avium- } \\
\text { intracellulare } \\
\text { ii.Mycobacterium } \\
\text { tuberculosis } \\
\text { iii. Hemophilus influenzae } \\
\text { iv. Streptococcus pneumoniae } \\
\text { v. Nocardia sp. } \\
\text { vi.Mycobacterium Kansasii } \\
\text { vii.Legionella spp. }\end{array}$ & $\begin{array}{l}\text { Dissemination } \\
\text { Dissemination } \\
\text { Pneumonia } \\
\text { Pneumonia } \\
\text { Pneumonia } \\
\text { Pneumonia } \\
\text { Pneumonia }\end{array}$ \\
\hline
\end{tabular}

II. Non-infectious
A. Kaposi's sarcoma
B. Non-Hodgkin's lymphoma

to cause morbidity in AIDS patient.

\section{Other infections}

Infection with legionella, Group B Streptococcus, Branchamella catarrhalis, Staphylococcus aureus, Nocardia and Aspergillus have been described in AIDS patients. Bronchial presence of Toxoplasma Gondii and Cryptosporidium have also been reported.

\section{Non-infectious Pulmonary Disease}

Kaposi's sarcoma is the most common malignancy involving the tracheobronchial tree and pleura, as well as the lung parenchyma in AIDS patients. The lack of desaturation with exercise and air flow obstruction, suggest tumor involvement rather than infection. The endobronchial appearance is characteristic, as reddish lesions are seen. The yield on biopsy is only 24 percent. The incidence of nonHodgkins lymphoma has been on the increase too. The lungs are involved in a few of these cases. ${ }^{15}$ The different types of pulmonary involvement in AIDS patients and approaches to therapy are summarized in tables 1 and 2.

\section{Diagnostic approach}

Pulmonary involvement in AIDS is so varied that a differential diagnosis must be entertained. If bronchoscopy with a Broncho Alveolar Lavage (BAL) and transbronchial lung biopsy is non-diagnostic, an open lung biopsy may be considered. Empiric therapy maybe given according to clinical presentation. A schematic representation of the dragnostic approach is given in Figure 1.

\section{Prevention}

A vaccine is currently under trial and 'safe' sex is being promoted, but in spite of joint efforts on the part of many countries the disease continues to assume epidemic proportions. Over 1.5 million people, or about one in every thirty men between the ages of twenty and fifty may already carry the virus. Wide scale testing is thus being adivsed. A sum of $\$ 75,000$ is estimated per patient, for hospital and medical treatment costs, from diagnosis till death. It is time the public be made aware of the full impact of the disease, and laws be enacted to stem transmission of the virus without infringing upon civil liberties of the public. emia. The disease may be mild, or progress to Adult Respiratory Distress Syndrome (ARDS). The diagnosis requires tissue or cytology material, usually from a lung biopsy, showing histologic evidence of typical intranuclear inclusion bodies. Dihydropropoxymethylguanine (DHPG) has been tried with some success. Interferon is also thought to be promising. Other viruses like Herpes simplex, Herpes zoster and Epstein- Barr virus are also known 
Table 2: Therapy for AIDS-Related Pulmonary Infections

\section{Phase}

Unconfirmed

suspicion of

AIDS-related

pulmonary

involvement

Established diagnosis

Failure or unacceptable side effects

Improvement resolution
Aggressive support. Vigilance for additional infections

Nonspecific Treatment

Aggressive support.* Diagnostic workup (BAL, bone marrow/lymph node/liver biopsy).

Repeated attempts to find additional infections

Close observation for relapse, recurrence, or new infections
Specific Treatment

Empiric TMP-SMX,** IV, or pentamidine, IM/IV in sick patients. Empiric anti-TB therapy in high-risk patients (e.g. Haitians, TB contacts)

No empiric therapy for other infections

TMP-SMX, IV, or pentamidine, IM/IV for PCP + (2-3 weeks). AntiTB therapy (drug selection based on history) for TB. Amphotericin B, IV, for fungi and multidrug regimens for MAIa + t; experimental drugs for CMVa

Switch drugs in PCP; experimental drugs if both failed. Add drugs in TB or mycoses

Prophylaxis in PCP. Standard 9-month therapy in TB. Long-term continuation of therapy in mycoses.

a Experimental treatment modalities of unproven value.

*Broncho - alveolar lavage

**Trimethoperim/Sulfamethoxazole

†Pneumocystis carinii pneumonia † Mycobacterium avium intracellulare

Table 3. A Practical approach to Pulmonary Infections in AIDS

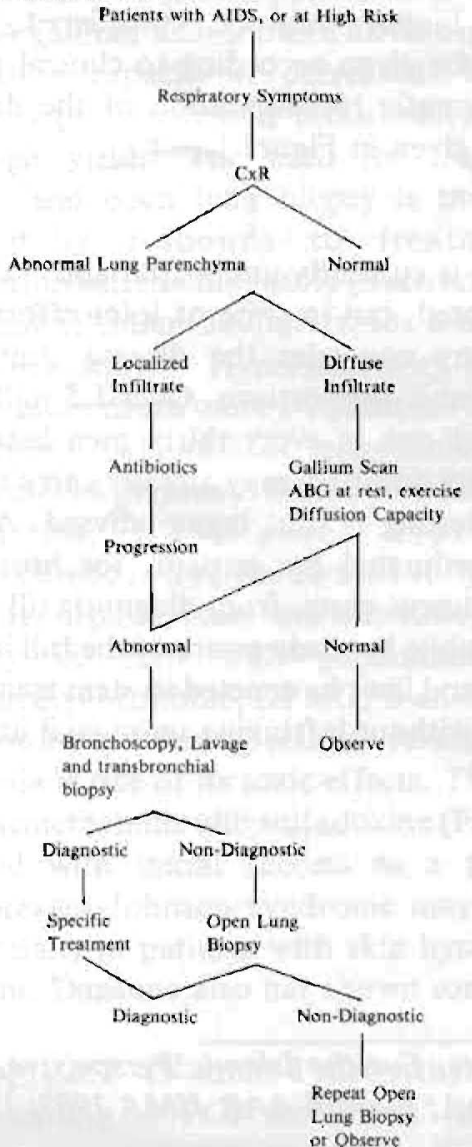

\section{References}

1. Jett JR, et al: Acquired immuno deficiency syndrome associated with blood-product transfusions. Ann Intern Med 1983; 99:621-24

2. Levy JA, et al: Isolation of lymphocytopathic retrovirus from San Francisco patients with AIDS. Science 1984; 225:840-42

3. Levy RM, Brudesen DE, and Rosenblum ML: Neurological manifestations of the acquired immunodeficiency syndrome (AIDS): Experience at UCSF and review of the literature. J Neurosurg $64: 475$

4. Weiss SH, et al: Screening test for HTLV-III (AIDS agent) antibodies. Specificity, sensitivity, and applications. JAMA 1985; 253:221-25

5. Kovacs JA, Masur H: Opportunistic infections in AIDS: Advances in host defense mechanisms. New York, Raven Press, 1985, vol 5, pp 35-58

6. Stover DE, et al: The usefulness of bronchoalveolar lavage in diagnosing infiltrates in the immunocompromised host. Ann Intern Med 1984: 76:101-17

7. Haverkos HW: Assessment of therapy for Pneumocustis carinii pneumonia. Am J Med 1984; 76:501-508

8. Gordin FM, Simon GL, Wofsy CB, and Mills J: Adverse reactions to trimethoprimsulfamethoxazone in patients with the acquired 
immunodeficiency syndrome. Ann Intern Med 1984; 100:495-99

9. Donath J, Khan FA: Pulmonary infections in AIDS. Compr Ther 1987; 13:49-58

10. Pape JW, et al: Characteristics of the acquired immunodeficiency syndrome (AIDS) in Haiti. N Engl J Med 1983; 309:945-50

11. Pitchenik AE, Rubinson HA; The radiographic appearance of tuberculosis in patients with the acquired immune deficiency syndrome (AIDS) and pre-AIDS. An Rev Respir Dis 1985; 131:393-96

12. Polsky B, Gold JWM, Whimbery E, et al: Baterial pneumonia in patients with the acquired immunodeficiency syndrome. Ann Intern Med $1986 ; 104: 38-41$

13. Zuger A, Louie E, Holzman RS, et al: Cryptococcal disease in patients with the acquired im- munodeficiency syndrome. Ann Intern Med $1986 ; 104: 234-40$

14. Kovacs JA, Krovacs AA, Polis M, et al: Cryptococcosis in the acquired immunodeficiency syndrome. Ann Intern Med 1985; 103:533-38

15. Safai B, and Koziner B: Malignant neoplasms in AIDS. In V.T. DeVita, S. Hellman, and S.A. Rosenberg (eds), AIDS: Etiology, diagnosis, treatment, and prevention. Philadelphia: J.B. Lippincott. 1984; pp 213-22.

16. Gottlieb MS, Knight S, Mitsuyasu R, et al: Prophylaxis of pneumocystis carinii, pneumonia in AIDS with pyrimethamine-Sulfadoxine (Fansidar). Lancet $1984 ; 2: 398-99$

17. Hughes WT, and Smith BC: Efficiency of Diaminodiphenylsulfone and other drugs in Murine Pneumocystis Carinii Pneumonitis. Antimicrob Agents Chemo Ther 1984; 26:436-40

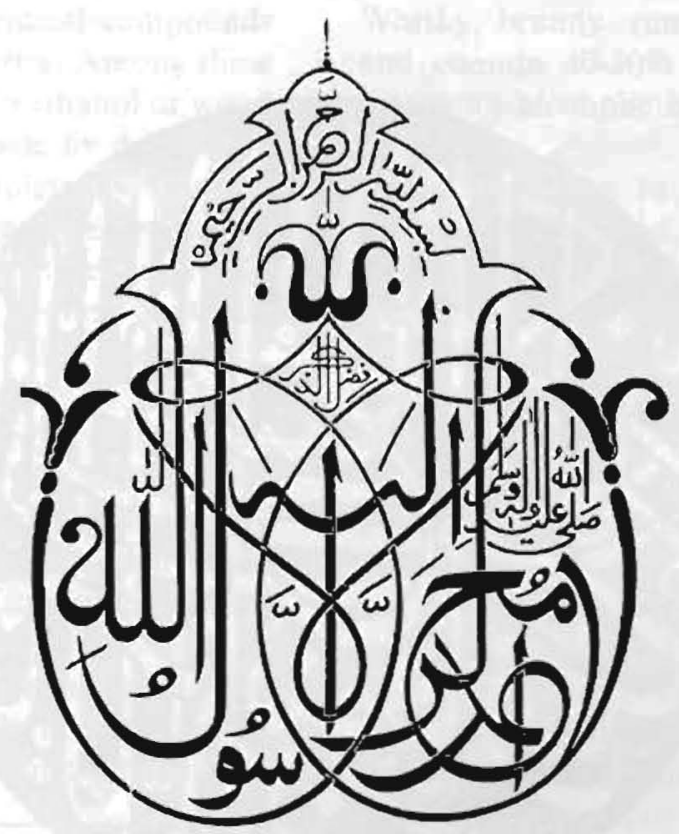

